\title{
D-Fagomine lowers postprandial blood glucose and modulates bacterial adhesion
}

\author{
Livia Gómez ${ }^{1} \dagger$, Eunice Molinar-Toribio ${ }^{2} \dagger$, María Ángeles Calvo-Torras ${ }^{3}$, Carles Adelantado ${ }^{3}$, \\ M. Emília Juan ${ }^{4}$, Joana M. Planas ${ }^{4}$, Xavier Cañas ${ }^{5}$, Carles Lozano ${ }^{1}$, Sergio Pumarola ${ }^{1}$, Pere Clapés ${ }^{2}$ \\ and Josep Lluís Torres ${ }^{2 *}$ \\ ${ }^{1}$ Bioglane SLNE, Tavern 17, 08006 Barcelona, Spain \\ ${ }^{2}$ Institute for Advanced Chemistry of Catalonia (IQAC), CSIC, Jordi Girona 18-26, 08034 Barcelona, Spain \\ ${ }^{3}$ Facultat de Veterinària, Universitat Autònoma de Barcelona, Bellaterra, Spain \\ ${ }^{4}$ Departament de Fisiologia and Institut de Recerca en Nutrició $i$ Segurat Alimentària (INSA-UB), Universitat de Barcelona \\ (UB), Avinguda Joan XXIII s/n, 08028 Barcelona, Spain \\ ${ }^{5}$ Barcelona Science Park, Baldiri Reixac 4-6, 08028 Barcelona, Spain
}

(Submitted 14 March 2011 - Final revision received 3 August 2011 - Accepted 8 August 2011 - First published online 3 October 2011)

\begin{abstract}
D-Fagomine is an iminosugar originally isolated from seeds of buckwheat (Fagopyrum sculentum Moench), present in the human diet and now available as a pure crystalline product. We tested D-fagomine for activities connected to a reduction in the risk of developing insulin resistance, becoming overweight and suffering from an excess of potentially pathogenic bacteria. The activities were: intestinal sucrase inhibition in vitro (rat mucosa and everted intestine sleeves), modulation of postprandial blood glucose in rats, bacterial agglutination and bacterial adhesion to pig intestinal mucosa. When ingested together with sucrose or starch, D-fagomine lowered blood glucose in a dose-dependent manner without stimulating insulin secretion. D-Fagomine reduced the area under the curve (0-120 min) by $20 \%$ $(P<0.01)$ and shifted the time to maximum blood glucose concentration $\left(T_{\max }\right)$ by $15 \mathrm{~min}$ at doses of $1-2 \mathrm{mg} / \mathrm{kg}$ body weight when administered together with $1 \mathrm{~g}$ sucrose/kg body weight. Moreover, D-fagomine (0.14 mm) agglutinated $60 \%$ of Enterobacteriaceae (Escherichia coli, Salmonella enterica serovar Typhimurium) populations $(P<0 \cdot 01)$, while it did not show this effect on Bifidobacterium spp. or Lactobacillus spp. At the same concentration, D-fagomine significantly $(P<0 \cdot 001)$ inhibited the adhesion of Enterobacteriaceae (95-99\% cells in the supernatant) and promoted the adhesion of Lactobacillus acidophilus (56\% cells in the supernatant) to intestinal mucosa. D-Fagomine did not show any effect on bacterial cell viability. Based on all this evidence, D-fagomine may be used as a dietary ingredient or functional food component to reduce the health risks associated with an excessive intake of fast-digestible carbohydrates, or an excess of potentially pathogenic bacteria.
\end{abstract}

Key words: Fagomine: Iminosugars: Insulin resistance: Weight management: Microbiota

D-Fagomine (1,2-dideoxynojirimycin) is a six-membered ring iminocyclitol that was first isolated from seeds of buckwheat (Fagopyrum sculentum Moench, Polygonaceae) ${ }^{(1)}$ and is also present in other plant sources such as mulberry (Morus Alba, Moraceae) leaves ${ }^{(2)}$ and gogi (Lycium chinense) roots $^{(3)}$. Iminocyclitols, also referred to as iminosugars, are carbohydrate analogues in which the endocyclic oxygen has been replaced by nitrogen (Fig. 1) and the spatial configurations of the hydroxyl groups are coincident with those of sugars (e.g. glucose, galactose, fucose and mannose). D-Fagomine was the first iminosugar found in plants and it is present in the human diet, since buckwheat flour is used in the elaboration of many traditional foods including Japanese soba noodles, French galletes de Bretagne and Italian polenta. Another common iminocyclitol is 1-deoxynojirimycin (DNJ), which is the most abundant iminosugar found in mulberry ${ }^{(4)}$. D-Fagomine presents the molecular configuration of D-glucose and D-mannose on carbons 3,4 and 5, while DNJ is a sugar mimetic of D-glucose. D-Fagomine and DNJ are particularly stable compounds, both chemically and metabolically ${ }^{(5)}$.

DNJ and other iminosugars are inhibitors of intestinal disaccharidases such as sucrase, lactase and maltase as well as other

Abbreviations: DNJ, 1-deoxynojirimycin; GI, glycaemic index; GL, glycaemic load; IR, insulin resistance.

*Corresponding author: J. L. Torres, fax +34 93204 5904, email joseplluis.torres@iqac.csic.es

† L. G. and E. M.-T. contributed equally to this work 
(a)

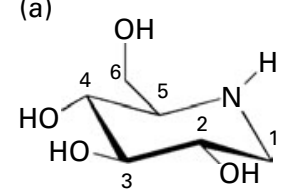

(b)

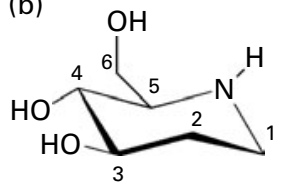

(c)

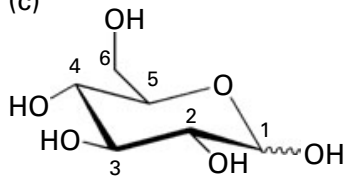

(d)

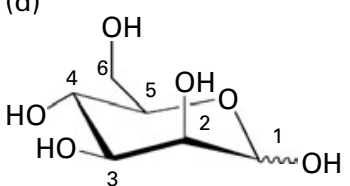

Fig. 1. Chemical structures of iminocyclitols (a) 1-deoxynojirimycin and (b) D-fagomine) compared to configurationally similar monosaccharides ((c) D-glucose and (d) D-mannose).

glycosidases (i.e. exo- and endosaccharidases) that break down oligomeric and polymeric saccharides ${ }^{(2,6)}$. This inhibitory effect has the potential to quench and delay the hyperglycaemic response to oral sucrose and starch. This is nutritionally relevant because persistent hyperglycaemia from carbohydrate abuse may lead to insulin resistance (IR), elevated fasting blood glucose and excess weight. IR, elevated fasting blood glucose, increased waist circumference, dyslipidaemia and high blood pressure are factors in the so-called metabolic syndrome ${ }^{(7)}$. IR may develop into type 2 diabetes which carries with it a major risk of CVD which are by far the leading cause of morbidity and mortality in many countries, including the USA ${ }^{(8)}$. Obesity and type 2 diabetes are considered modern epidemics, and their incidence is particularly alarming among children and adolescents ${ }^{(9)}$. The problem is far from being satisfactorily addressed, considering the high availability and low cost of energy-dense foods compared to low-energy-density healthier alternatives ${ }^{(10,11)}$.

As iminocyclitols are sugar mimetics, they may also have the capacity to inhibit the protein-carbohydrate-mediated adhesion of bacteria to epithelial surfaces. This may be an important activity because the virulence of potentially deleterious strains such as Escherichia coli and Salmonella enterica serovar Typhimurium is associated with their tight adhesion to mucosal surfaces, typically through lectins expressed in the tip of their fimbriae ${ }^{(12)}$ while putatively beneficial bacteria, such as probiotic strains of Lactobacillus spp. and Bifidobacterium spp., are more loosely attached ${ }^{(13)}$. This would again be a particularly important activity of iminosugars, as the composition of the intestinal microbiota is influenced by dietary habits and gut micro-organisms play a role in the regulation of the host's energy homeostasis and fat storage ${ }^{(14)}$. The activity of iminosugars as antiadhesive binding agents and their potential role as modulators of bacterial adhesion have not been extensively researched. A recent paper linked the iminosugar DNJ to the inhibition of Streptococcus mutans biofilm formation ${ }^{(15)}$. Other authors ${ }^{(16)}$ reported that the antiadhesive effect of hydrophobic $N$-alkylated-DNJ was due to the hydrophobic moiety, since DNJ itself was inactive.

In the search for new nutritional tools to reduce the risk of developing IR and becoming overweight, we considered D-fagomine (Fig. 1), a mild glycosidase inhibitor ${ }^{(17)}$, as a suitable candidate for a dietary ingredient and functional food component. Nothing has yet been reported concerning the effects of orally administered D-fagomine, possibly because, as a weak inhibitor in vitro, it has always been assumed that its in vivo efficacy would be limited. The only in vivo effect claimed for D-fagomine was the stimulation of insulin release after intraperitoneal administration to streptozotocin-diabetic mice $^{(18)}$. We also considered that, due to its structural similarity with D-mannose, D-fagomine could have some effects on bacterial adhesion. There are no previous reports of any antiadhesive activity of D-fagomine. The lack of information on the activities of oral D-fagomine may also be due to low availability from both natural and synthetic sources. However, an elegant and expedient chemo-enzymatic method has now been developed which is opening up the possibility of obtaining pure crystalline $\mathrm{D}$-fagomine in $\mathrm{g}$ to kg quantities for thorough testing ${ }^{(19,20)}$. Using this preparation, we examine in the present study the modulation of both postprandial blood glucose concentration and bacterial adhesion by $\mathrm{D}$-fagomine.

\section{Materials and methods}

\section{Reagents}

D-Fagomine, provided by Bioglane (Barcelona, Spain) was manufactured following the patented proprietary enzymatic catalysis procedure described in WO2008025826A1. We used the resulting crystalline pure (assay 98\%) preparation of D-fagomine (Fagopure ${ }^{\circledR}$ ) to evaluate the activity of D-fagomine along the intestinal tract as a modulator of both glycosidase activity and bacterial adhesion. Other reagents and chemicals were: DNJ (Carbosynth Limited, Compton, Berkshire, UK), miglitol (Zhejiang Medicine Company Limited, Xinchang Pharma, Chengguan Town, China), acarbose (Serva Electrophoresis GmbH, Heidelberg, Germany), sucrose (SigmaAldrich, St Louis, MO, USA), starch (maize starch C-TEX 06 201; Cargill-Cerestar, Martorell, Spain), phloridzin dihydrate (Sigma-Aldrich, St Louis, MO, USA), ketamine chlorhydrate (Imalgene 1000; Merial Laboratorios S.A., Barcelona, Spain), xylacine (Rompun 2\%; Química Farmacéutica S.A., Barcelona, Spain), 4-hydroxybenzoic acid (Sigma-Aldrich, Steinheim, Germany), 4-aminoantipyrine (Sigma-Aldrich, St Louis, MO, USA), Glucose oxidase type II-S from Aspergillus niger (Sigma-Aldrich, Steinheim, Germany), Peroxidase Type II from horseradish (Sigma-Aldrich, St Louis, MO, USA), Tris (hydroxymethyl)aminomethane (Tris; Roche Diagnostics, Meinheim, Germany). Water for the preparation of buffers and other assay solutions was obtained using a water purification Milli-Q system (Millipore Corporation, Billerica, MA, USA).

\section{Rats and diets}

A total of seventy-seven adult male Sprague-Dawley rats of 175-250 g body weight (Janvier, Le Genest-St-Isle, France) were housed in cages ( $n$ 3-4/cage) under controlled conditions of stable humidity $(40-77 \%)$, and temperature $\left(23^{\circ} \mathrm{C}\right)$ with a $12 \mathrm{~h}$ light $-12 \mathrm{~h}$ dark cycle. The rats were fed ad libitum 
a standard diet (Panlab A04; Panlab, Barcelona, Spain) and given water. To minimise circadian rhythm effects, rat manipulations were carried out in the morning. Handling and killing of the animals were in full accordance with the European Union guidelines for the care and management of laboratory animals and the pertinent permission was obtained from the CSIC Subcommittee of Bioethical Issues (ref. AGL200912374-C03-03). The authors further attest that all efforts were made to minimise the number of animals used and their suffering.

\section{Sucrose/starch-loading test}

The sucrose/starch-loading test was performed after a $12 \mathrm{~h}$ food deprivation period. A solution of sucrose or starch (1 or $2 \mathrm{~g} / \mathrm{kg}$ body weight) together with the appropriate amount of the compound being tested was administered to the rats. Negative and positive control experiments were performed by administration of only water and carbohydrate solutions, respectively. The appropriate doses of D-fagomine (1, 2, $4 \mathrm{mg} / \mathrm{kg}$ body weight), DNJ, miglitol ( $N$-hydroxyethylDNJ) and acarbose $(2 \mathrm{mg} / \mathrm{kg}$ body weight) were administered as water solutions $(5 \mathrm{ml} / \mathrm{kg}$ body weight) using a gastric probe. We used four or five animals for each condition tested. Blood samples were collected from the saphenous vein $^{(21)}$ at $0,15,30,45,60,90$ and $120 \mathrm{~min}$ after administration. Blood glucose concentration was measured by the enzyme electrode method using a blood glucose meter Ascensia ELITE XL (Bayer Consumer Care AG, Basel, Switzerland). Insulin concentration was measured using the rat/mouse insulin ELISA kit from Millipore Corporation, in plasma obtained from blood samples $(0 \cdot 1 \mathrm{ml})$ collected into tubes containing EDTA at 0, 8, 15, 30, 60 and $120 \mathrm{~min}$ after administration. The plasma was kept at $-80^{\circ} \mathrm{C}$ until analysis.

Sucrase activity measurements on tissue homogenates and everted intestine sleeves

The activity of brush-border sucrase (glycosidase EC 3.2.1.48) was assayed on jejunal mucosa and everted intestine sleeves following Dahlqvist ${ }^{(22)}$ and Lee et al. ${ }^{(23)}$. For the preparation of gut mucosal homogenates, the rats were fasted overnight and then anaesthetised with ketamine chlorhydrate $(90 \mathrm{mg} / \mathrm{kg}$ body weight intraperitoneally) and xylacine $(10 \mathrm{mg} / \mathrm{kg}$ body weight intraperitoneally). The anaesthetised rats were killed by cervical dislocation. The small intestine was removed, and carefully divided into duodenum, jejunum and ileum. The jejunum was washed with ice-cold isotonic saline $(5 \mathrm{ml})$, opened lengthwise and the mucosa scraped off with a microscope slide. The samples were added to ice-cold isotonic saline (50 mg mucosa/ml) and homogenised using a T10 basic Ultra-Turrax (IKA, Staufen, Germany). Sucrase activity was determined by colorimetric measurement of the glucose release by the action of sucrase on sucrose, according to the classic procedure in Dahlqvist ${ }^{(22)}$. Each product (D-fagomine, DNJ, miglitol, acarbose) was tested on the mucosa of five rats at concentrations ranging from $0.2 \mathrm{~nm}$ to $1 \mathrm{~mm}$ in the presence of $0 \cdot 1 \mathrm{~m}$-sucrose (substrate). Inhibitors $(5 \mu \mathrm{l})$ and suitably diluted homogenised mucosa $(95 \mu \mathrm{l})$ were pre-incubated $(30 \mathrm{~min}$ at $\left.37^{\circ} \mathrm{C}\right)$; then the reaction was carried out in phosphate buffer $\mathrm{pH} 6.8(300 \mathrm{ml})$ by the addition of the substrate $(0 \cdot 1 \mathrm{ml})$. Substrate, inhibitor and homogenised mucosa were incubated together $\left(30 \mathrm{~min}\right.$ at $37^{\circ} \mathrm{C}$ and $\left.250 \mathrm{rpm}\right)$ in triplicate. The reaction was terminated by the addition of Glucostat solution $(2 \mathrm{ml})$ (Tris $0.5 \mathrm{~m}$; 4-hydroxybenzoic acid $10 \mathrm{~mm}$; 4-aminoantipyrine $0.4 \mathrm{~mm}$; glucose oxidase $1480 \mathrm{IU} / \mathrm{l}(24.672 \mu \mathrm{katal} / \mathrm{l})$, peroxidase $250 \mathrm{IU} / \mathrm{l}(4 \cdot 167 \mu \mathrm{katal} / \mathrm{l}), \mathrm{pH} 7 \cdot 3)$. After further incubation $(2 \cdot 5 \mathrm{~h}$ at $37^{\circ} \mathrm{C}$ ), the amount of glucose was measured at $505 \mathrm{~nm}$ using an ELISA reader and ninety-six-well plates. Enzyme activity ( $\mu$ mol of substrate hydrolysed/h) was normalised to protein content evaluated by the Bradford method ${ }^{(24)}$.

To prepare the everted intestine sleeves, the jejunum was obtained as described previously, flushed with ice-cold isotonic saline $(5 \mathrm{ml})$ and cut into 3 -cm-long segments that were weighed. Each segment was everted using a plastic pipette tip (yellow) and both ends were secured by tying knots. The brush-border membrane facing the lumen in vivo now faced outwards. Because the glucose released by the action of sucrase would be taken up into the tissue by the GLUT, this was inhibited by pre-incubating the sleeves $(30 \mathrm{~min}$ at $37^{\circ} \mathrm{C}$ and $250 \mathrm{rpm}$ ) in Ringer's solution containing the GLUT inhibitor phloridzin $(0.5 \mathrm{~mm})^{(23)}$. The sleeves then were incubated $\left(16 \mathrm{~min}\right.$ at $37^{\circ} \mathrm{C}, \mathrm{pH} 7.3$ and $250 \mathrm{rpm}$ ) in Ringer's solution $(5 \mathrm{ml})$ containing sucrose $(50 \mathrm{~mm})$ as well as phloridzin $(0.5 \mathrm{~mm})$ and the appropriate concentration of the inhibitor ( $0.2 \mathrm{~nm}$ to $1 \mathrm{~mm})$. After incubation, the sleeves were removed and aliquots $(500 \mu \mathrm{l})$ of the incubation solution were added to tubes containing Glucostat solution $(2 \mathrm{ml})$ in triplicate. These were then incubated $\left(2 \mathrm{~h}\right.$ at $37^{\circ} \mathrm{C}$ and $\left.250 \mathrm{rpm}\right)$ and afterwards absorbance at $505 \mathrm{~nm}$ was read on a SpectraMax M5 spectrophotometer (Molecular Devices, Sunnyvale, CA, USA). Sucrase activity ( $\mu \mathrm{mol}$ of substrate hydrolysed/h) was normalised to $\mathrm{mg}$ of wet weight of the intestinal sleeve.

\section{Bacterial agglutination}

The strains used were obtained from the Bacterial Strain Collection of the Faculty of Veterinary Science at the Universitat Autònoma de Barcelona. Overnight cultures of each bacterial strain were inoculated into 100-ml flasks containing Luria medium to facilitate the production of fimbriae. The strains were incubated at $37^{\circ} \mathrm{C}$ for $24 \mathrm{~h}$. Colonies were grown on Luria medium Agar plates (Liofilchem, Roseto degli Abruzzi, Italy) and after $24 \mathrm{~h}$ of incubation, several dilutions were prepared in PBS for each strain, down to a concentration of $10^{8}$ colony-forming units $/ \mathrm{ml}$. Bacterial suspensions in the presence of D-fagomine at final concentrations of 20 and $200 \mathrm{mg} / \mathrm{l}(0.14$ and $1.4 \mathrm{~mm})$ were incubated for $90 \mathrm{~min}$ at room temperature. The suspensions were spread onto slides, observed under an optical microscope and compared with negative control cultures and positive control suspensions obtained with mannose $0 \cdot 05 \mathrm{M}$. A minimum of twenty fields were evaluated for aggregations. The results were expressed as percentages of aggregation related to the number of aggregations obtained with mannose $0 \cdot 05 \mathrm{M}(100 \%)$. 


\section{Bacterial adhesion to intestinal mucosa}

The mucosa was obtained from intestinal segments of pigs, just after they were killed at a local slaughterhouse, and kept frozen until use. The mucosa preparation $(1 \mathrm{ml})$ was defrosted, centrifuged and mixed with PBS $(99 \mathrm{ml})$. Before each test, the concentration of mucin in the suspension was calculated by the Bradford method ${ }^{(24)}$. Multiwell plates (Nunc ${ }^{\circledR}$; Nunc A/S, Roskilde, Denmark) were coated by incubation with the mucosa suspension $(2.5 \mathrm{ml})$ overnight at $4^{\circ} \mathrm{C}$. Then the unbound mucosa was carefully sucked off and the wells gently loaded with bacterial suspensions $\left(10^{7}\right.$ colonyforming units $/ \mathrm{ml}$ ) followed immediately by the addition of the appropriate amount of $\mathrm{D}$-fagomine to reach the desired final concentrations ( 10 and $20 \mathrm{mg} / 1,0.07$ and $0.14 \mathrm{~mm}$ ) in a total volume of $1.5 \mathrm{ml}$. The mixtures were incubated at $37^{\circ} \mathrm{C}$ for $90 \mathrm{~min}$. Mannose $0.05 \mathrm{~m}$ was used as a positive control and the experiment was performed in triplicate. Finally, the colony-forming units from both the supernatant and mucosa were counted under an optical microscope after cultivating both fractions overnight.

\section{Statistics}

The results from the sucrase inhibition tests are expressed as mean values with their standard errors. Student's $t$ test (twotailed distribution) was carried out to analyse the differences between the two assays. We applied a non-linear sigmoid dose-response inhibition approximation model to derive the $\mathrm{IC}_{50}$ values for enzyme inhibition. The areas under the curve from the sucrase/starch-loading tests were calculated using the trapezoidal rule. Statistical differences were evaluated by two-way ANOVA and Bonferroni's post test. Results with $P<0.05$ were taken as significant. All data manipulation and statistical analysis were performed using Graph Pad Prism 4 (Graph Pad Software, Inc., San Diego, CA, USA).

\section{Results}

\section{Effect of D-fagomine on postprandial blood glucose in vivo}

D-Fagomine lowered postprandial glycaemia in SpragueDawley rats following the intake of sucrose and starch (Fig. 2). D-Fagomine effectively modulated postprandial glycaemia in a dose-dependent manner (Fig. 3) that resulted in a reduction in area under the curve at $120 \mathrm{~min}$ between $17 \%$ (1 mg D-fagomine/kg body weight $)(P<0.01)$ and $43 \%$ ( $4 \mathrm{mg}$ D-fagomine $/ \mathrm{kg}$ body weight) $(P<0 \cdot 001)$ after the intake of $1 \mathrm{~g}$ sucrose $/ \mathrm{kg}$ body weight. No significant differences $(P>0.05)$ between the doses of 1 and $2 \mathrm{mg}$ D-fagomine/kg body weight were recorded under our experimental conditions. D-Fagomine lowered the maximum blood glucose concentration from $5 \cdot 8 \mathrm{~mm}$ to $5 \cdot 4,4.8$ and $4.4 \mathrm{~mm}$ at doses of 1,2 and $4 \mathrm{mg} / \mathrm{kg}$ body weight, respectively, and shifted the time to maximum blood glucose concentration $\left(T_{\max }\right)$ from 15 to $30 \mathrm{~min}$ (doses of 1 and $2 \mathrm{mg}$ D-fagomine $/ \mathrm{kg}$ body weight) and to $45 \mathrm{~min}$ ( $4 \mathrm{mg}$ D-fagomine $/ \mathrm{kg}$ body weight) (Fig. 3). The efficiencies of D-fagomine, DNJ, miglitol ( $N$-hydroxyethyl-DNJ) and acarbose on blood glucose concentration in healthy Sprague-Dawley rats given a single dose of
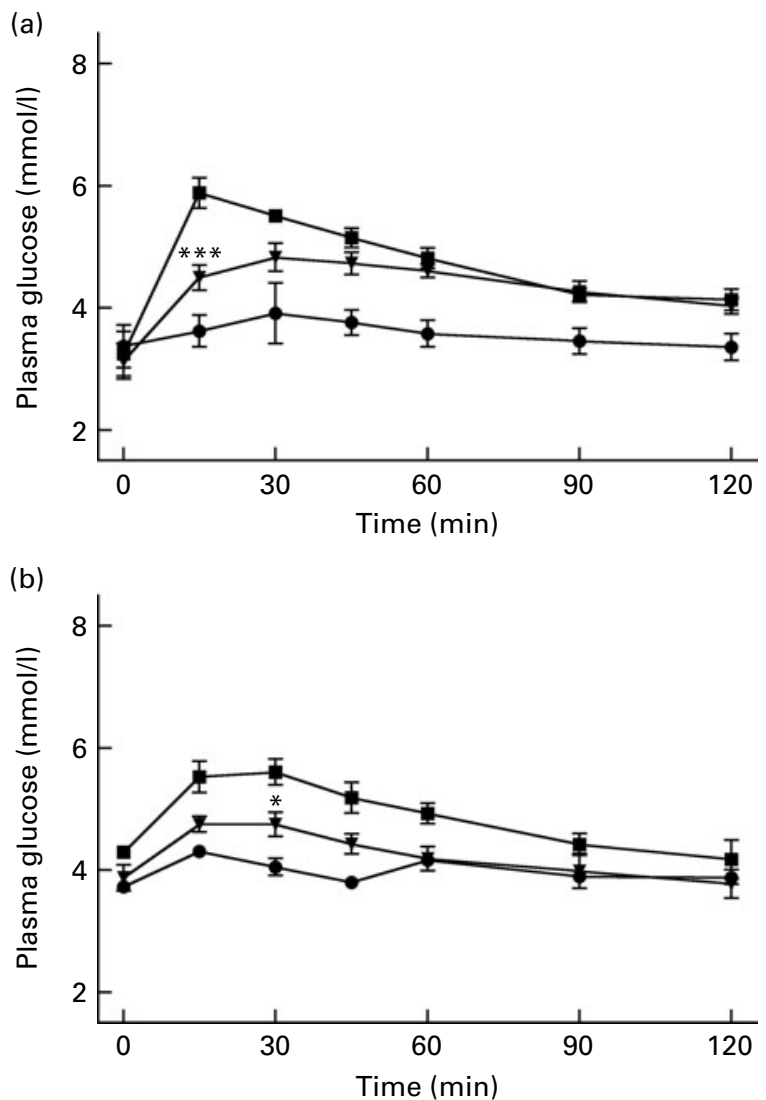

Fig. 2. Effect of $\mathrm{D}$-fagomine $(2 \mathrm{mg} / \mathrm{kg}$ body weight) on the glycaemic response of normal Sprague-Dawley rats after ingestion $(1 \mathrm{~g} / \mathrm{kg}$ body weight) of: (a) sucrose and (b) starch. Normal rats were food-deprived for $12 \mathrm{~h}$ and then administered the carbohydrate and D-fagomine together. $\longrightarrow$, Sucrose $(1 \mathrm{~g} / \mathrm{kg}) ; \longrightarrow$, sucrose + D-fagomine $(2 \mathrm{mg} / \mathrm{kg}) ; \longrightarrow$ vehicle (water). Values are means with their standard errors of mean. Mean values were significantly different from the control: ${ }^{*} P<0.05$, ${ }^{\star \star \star} P<0.001$.

sucrose were of the same order of magnitude. Acarbose, which is not an iminosugar, was the most effective agent tested. These comparative results are included as Supplemental Fig. S1 (available online at http://www.journals.cambridge.org/ bjn). D-Fagomine did not show any effect on postprandial glycaemia after the intake of glucose (dose-response curves included as Supplemental Fig. S2 available online at http:// www.journals.cambridge.org/bjn), which suggests that it did not affect glucose transport across the small intestine. In agreement with this, D-fagomine has been observed to have no effect on the transport of D-glucose $(5 \mathrm{~mm})$ in cultures of intestinal Caco-2 cells ( $\mathrm{R}$ Martín-Venegas and R Ferrer, personal communication). Postprandial blood insulin concentration decreased in accordance with the decrease in blood glucose concentration (Fig. 4), which indicates that D-fagomine did not stimulate fast insulin secretion.

\section{Intestinal disaccharidase inhibitory activity in vitro}

The in vitro sucrase inhibitory activity of D-fagomine, DNJ, miglitol and acarbose was measured on preparations of homogenised intestinal mucosa and on sections of everted small intestine (Table 1). The outcomes of the two in vitro assays 


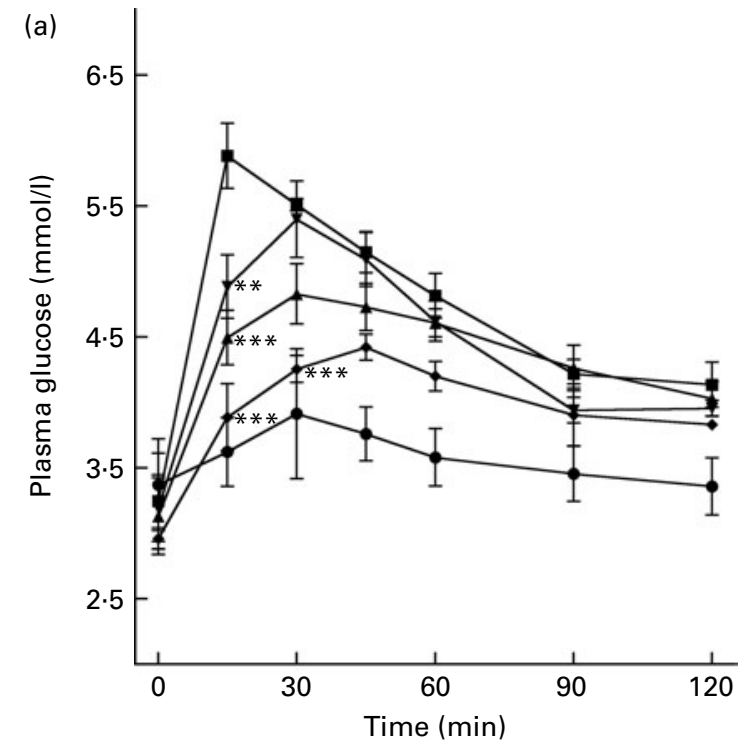

(b)

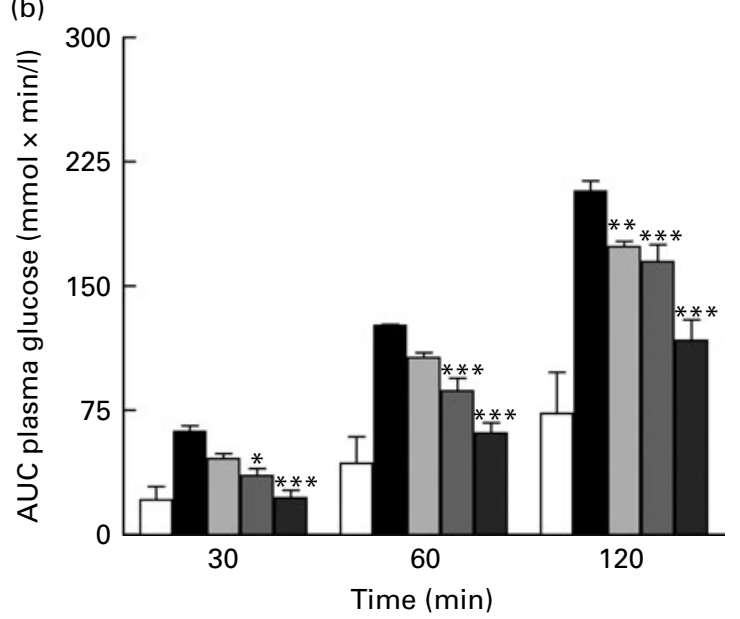

Fig. 3. Dose-dependent effect of D-fagomine on the glycaemic response of normal Sprague-Dawley rats after ingestion of sucrose (1 $\mathrm{g} / \mathrm{kg}$ body weight). Normal rats were food-deprived for $12 \mathrm{~h}$ and then administered the carbohydrate and D-fagomine together. AUC, area under the curve. (a) $\longrightarrow$ sucrose $(1 \mathrm{~g} / \mathrm{kg}) ; \longrightarrow$, sucrose $+\mathrm{D}$-fagomine $(1 \mathrm{mg} / \mathrm{kg}) ; \longrightarrow$, sucrose + D-fagomine $(2 \mathrm{mg} / \mathrm{kg})$; $\longrightarrow$, sucrose + D-fagomine $(4 \mathrm{mg} / \mathrm{kg}) ; \longrightarrow$, vehicle (water). (b) $\square$, vehicle (water); $\square$, sucrose $(1 \mathrm{~g} / \mathrm{kg}) ; \square$, sucrose $+\mathrm{D}$-fagomine $(1 \mathrm{mg} / \mathrm{kg}) ; \quad$ 口, sucrose + D-fagomine $(2 \mathrm{mg} / \mathrm{kg}) ; \square$, sucrose + D-fagomine $(4 \mathrm{mg} / \mathrm{kg})$. Values are means with their standard errors of mean. Mean values were significantly different from the control: ${ }^{\star} P<0.05,{ }^{\star \star} P<0.01$, ${ }^{\star \star \star} P<0.001$.

were clearly different. Only the D-fagomine results were similar $(P>0.05)$ in both assays. On homogenised mucosa, D-fagomine was a weaker inhibitor than the other compounds between two and three orders of magnitude. In contrast, when everted intestinal membranes were used, the inhibitory potencies of D-fagomine and acarbose were similar, and the differences between D-fagomine and the other two compounds were lower.

\section{Agglutinating and antiadhesive activity of D-fagomine on fimbriated bacteria}

D-Fagomine modulated bacterial adhesion without affecting cell viability. At a concentration as high as $2000 \mathrm{mg} / \mathrm{l}$, D-fagomine was virtually inactive as antimicrobial agent against an array of different strains. The results of the inhibition tests are included in Supplemental Table S2 (available online at http://www.journals.cambridge.org/bjn). D-Fagomine agglutinated cells of $E$. coli and S. enterica serovar Typhimurium at concentrations of 20 and $200 \mathrm{mg} / \mathrm{l}$ with agglutinations of 60 and $70 \%$ of the control cultures, respectively $(P<0 \cdot 001)$. Fig. 5 illustrates this agglutination effect. Moreover, D-fagomine effectively prevented the adhesion of the same fimbriated bacterial strains on pig intestinal mucosa at concentrations of 10 and $20 \mathrm{mg} / 1(P<0.001)$ (Table 2). More than $95 \%$ of the Enterobacteriaceae were recovered in the supernatant. The effect was equivalent to that of a solution of mannose $0.05 \mathrm{~m}$ (i.e. $9000 \mathrm{mg} / \mathrm{l}$ ). At $20 \mathrm{mg} / \mathrm{l}$, D-fagomine did not affect the adhesion of Bifidobacterium sp. to intestinal mucosa and promoted the adhesion of Lactobacillus acidophilus $(P<0 \cdot 001)$ (Table 2).

\section{Discussion}

Natural iminosugars mimic the structures of sugars and may have the capacity to bind to the same loci within biological systems. Particularly D-fagomine is structurally related to D-glucose and D-mannose (Fig. 1). We first tested D-fagomine for the modulation of postprandial blood glucose with regard to potential applications in the reduction of the risk of developing IR and becoming overweight. D-Fagomine has been described before as a weak inhibitor of $\alpha$-glycosidases in in vitro assays using purified enzymes ${ }^{(19)}$ or homogenates of intestinal mucosa ${ }^{(25)}$. When we tested $\mathrm{D}$-fagomine in vivo, we found that it lowered postprandial blood glucose concentration in healthy rats given a single dose of sucrose. D-Fagomine was less efficient in doing so than acarbose, a non-absorbable inhibitor of both $\alpha$-glycosidases and $\alpha$-amylase, and similar in efficiency to DNJ, a more potent iminosugar in vitro ${ }^{(25)}$, and its derivative miglitol ( $N$-hydroxyethyl-DNJ). Then we corroborated that D-fagomine was a weaker sucrase inhibitor in vitro than DNJ, miglitol and acarbose (Table 1, first column). As the results were different in vitro and in vivo,

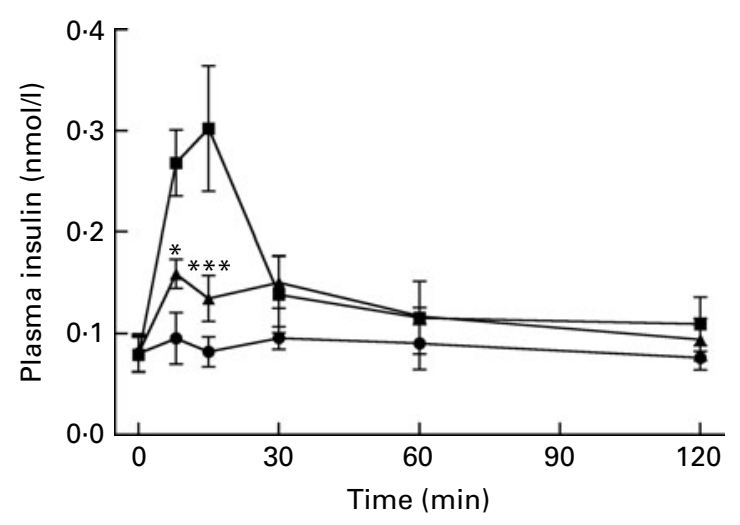

Fig. 4. Effect of $\mathrm{D}$-fagomine on the insulinaemic response of normal Sprague-Dawley rats after ingestion of sucrose ( $1 \mathrm{~g} / \mathrm{kg}$ body weight). Normal rats were food-deprived for $12 \mathrm{~h}$ and then administered the carbohydrate and D-fagomine together. $\longrightarrow$ - Sucrose $(1 \mathrm{~g} / \mathrm{kg})$; $\longrightarrow$, sucrose + D-fagomine $(2 \mathrm{mg} / \mathrm{kg})$; $\longrightarrow$, vehicle (water). Values are means with their standard errors of mean. Mean values were significantly different from the control: ${ }^{\star} P<0.05,{ }^{\star \star *} P<0.001$. 
Table 1. Inhibitory activity† of sugar mimetics on rat intestinal sucrase in vitro

( $\mathrm{IC}_{50}$ values with their standard errors of mean)

\begin{tabular}{|c|c|c|c|c|}
\hline \multirow[b]{3}{*}{ Compound } & \multicolumn{4}{|c|}{ Assay } \\
\hline & \multicolumn{2}{|c|}{$\begin{array}{l}\text { Intestinal mucosa } \\
\text { homogenate }\end{array}$} & \multicolumn{2}{|c|}{$\begin{array}{l}\text { Everted intestine } \\
\text { sleeves } \neq\end{array}$} \\
\hline & $\mathrm{IC}_{50}(\mu \mathrm{M})$ & SEM & $\mathrm{IC}_{50}(\mu \mathrm{M})$ & SEM \\
\hline D-Fagomine & $42 \cdot 0$ & 5.9 & $59 \cdot 0$ & $8 \cdot 1$ \\
\hline Acarbose & $1 \cdot 10^{\star}$ & 0.13 & $53 \cdot 0$ & 8.9 \\
\hline Miglitol & $0.150^{*}$ & 0.017 & $5 \cdot 20^{*}$ & 0.80 \\
\hline DNJ & $0.0270^{*}$ & 0.0030 & $0.77^{*}$ & 0.10 \\
\hline
\end{tabular}

DNJ, 1-deoxynojirimycin.

* Mean values were significantly different from those of $D$-fagomine within each assay $(P<0.001)$.

$\dagger$ Activity is given as $\mu \mathrm{mol}$ of sucrose hydrolysed/h.

$\ddagger$ Activity is normalised to $\mathrm{mg}$ of wet weight of the intestinal sleeve.

we tested the same compounds as sucrase inhibitors on everted intestine sleeves, an experimental set-up that is closer to the situation in vivo. This method is not commonly used because it is more experimentally complex than the method of homogenised mucosa and it has been shown that both preparations give similar sucrase activity ${ }^{(23)}$. While D-fagomine was still a mild inhibitor in the everted sleeve test, the differences in the absolute values of sucrase inhibition by DNJ, miglitol and acarbose between the two in vitro assays were of more than one order of magnitude (Table 1). The sucrase inhibitory potencies of $\mathrm{D}$-fagomine and acarbose in the everted sleeve test were similar, while those of DNJ and miglitol were approximately 10 -fold and 70-fold higher. These results indicate that experimental departure from the in vivo situation may result in large differences in the outcome of brush-border sucrase inhibition assays and that potent inhibitors in vitro may not be as effective in vivo. The in vitro assays may provide information about comparative efficiencies and the everted sleeves, a set-up closer to the in vivo situation, may be a better option than working with purified enzymes or homogenates. Whatever the choice is, special attention must be paid when extrapolating the results to postprandial blood glucose modulation. To make sure that putatively useful compounds are not overlooked, direct testing in vivo appears to be the best option.

As intraperitoneally administered D-fagomine induced insulin release and consequently lowered glycaemia in diabetic mice $^{(18)}$, stimulation of insulin secretion may be thought to account for the in vivo activity disclosed here. However, in our in vivo experiments, orally administered D-fagomine did not raise the blood insulin level (Fig. 3); on the contrary, as it lowered blood glucose, it also lowered the insulin response over the 2-h postprandial period. Moreover, D-fagomine did not show any effect on postprandial glycaemia after intake of glucose (Supplemental Fig. S2 available online at http:// www.journals.cambridge.org/bjn). These results imply that D-fagomine neither stimulated fast insulin secretion nor significantly affected glucose transport across the small intestine. Over the postprandial period, the action of $\mathrm{D}$-fagomine appears to be that of slowing down the glucose release from oligomeric and polymeric carbohydrates by inhibition of brush-border glycosidases. So D-fagomine lowers the socalled glycaemic load (GL) of a meal. The GL corresponding to a given foodstuff is calculated as the amount of carbohydrates in it multiplied by its glycaemic index (GI), the area under the curve of blood glucose from 0 to $2 \mathrm{~h}$ after ingestion of $50 \mathrm{~g}$ of carbohydrate ${ }^{(26,27)}$. The GL is thereby a measure of how much carbohydrates are incorporated systemically as glucose and how fast this occurs ${ }^{(26,27)}$. Low GI and GL diets have been associated with a reduced risk of becoming overweight by delaying the onset of hunger and limiting the storage of nutrients as fat ${ }^{(28)}$. While it is accepted that lowering the glycaemic response by glycosidase inhibitors and low GI foods both delay the onset of $\operatorname{IR}^{(29,30)}$, the question of whether diets with low GI and GL are effective at controlling excess weight is controversial ${ }^{(31)}$. A recent meta-analysis of randomised controlled trials and a more recent trial published later suggested that low-carbohydrate diets may only be associated with modest short-term weight $\operatorname{loss}^{(32,33)}$. It should be noted though that these trials were conducted on large genotypically and phenotypically heterogeneous populations. Clearer effects may well be evident from studies with subpopulations that are sensitive to carbohydrate-related weight gain. Supporting this view is the observation that early $(30 \mathrm{~min})$ postprandial insulinaemia predicted weight gain in humans and that there exists a subpopulation characterised by early highinsulin secretion that gains weight while consuming a low-fat $\operatorname{diet}^{(34)}$. Randomised controlled trials with D-fagomine and appropriate subpopulations may help to clarify the role of low-GL diets in weight gain and to confirm the reduction in the risk of developing type 2 diabetes associated with lowering postprandial glycaemia. Another controversial point involving lowering GL is that low-GI foods include ingredients that are poorly defined chemically (e.g. complex mixtures with unidentified minor components) and their mode of action is unclear. Moreover, most of these ingredients may alter the organoleptic and rheologic properties of the original foodstuff. As pure D-fagomine is effective at a concentration of $0 \cdot 1 \%$ in the matrix, the ingredient may allow the design of foodstuffs with controlled GI resulting in only minimal modification of the composition and the other properties.

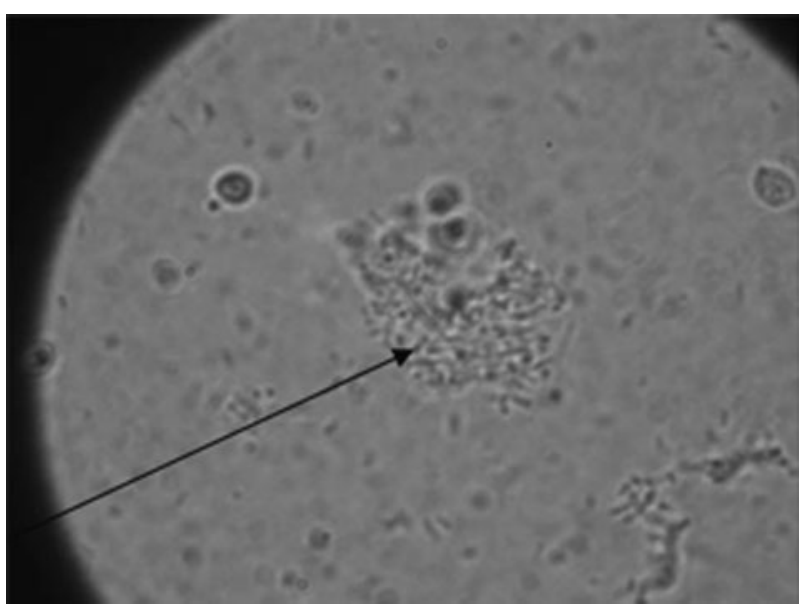

Fig. 5. Aggregation of Salmonella enterica serovar Typhimurium in a solution of $D$-fagomine in PBS (200 mg/l). 
Table 2. Influence of $D$-fagomine on the adhesion of bacteria to intestinal pig mucosa*

(Mean values of the logarithms of colony-forming units (CFU; total and supernatant) and percentage CFU in the supernatant)

\begin{tabular}{|c|c|c|c|c|c|c|}
\hline & \multicolumn{2}{|c|}{ Total } & \multicolumn{2}{|c|}{ Supernatant } & \multicolumn{2}{|c|}{ Supernatant } \\
\hline & Log CFU/ml & SEM & Log CFU/ml & SEM & $\% \mathrm{CFU}$ & SEM \\
\hline \multicolumn{7}{|l|}{ Control (PBS) } \\
\hline Salmonella enterica serovar Typhimurium FVB7654 & 8.59 & 0.01 & $6 \cdot 07$ & 0.00 & 0.30 & 0.01 \\
\hline S. enterica serovar Typhimurium FVB5643 & 8.60 & 0.00 & $6 \cdot 14$ & 0.00 & 0.35 & 0.01 \\
\hline Escherichia coli FVB2453 & $8 \cdot 60$ & 0.00 & $6 \cdot 16$ & 0.00 & 0.36 & 0.01 \\
\hline E. coli FVB3478 & 8.60 & 0.00 & $6 \cdot 18$ & 0.00 & 0.38 & 0.02 \\
\hline Lactobacillus acidophilus FVB1467 & $6 \cdot 69$ & 0.00 & 6.65 & 0.00 & 91.84 & 0.01 \\
\hline Bifidobacterium sp. FVB4278 & $7 \cdot 08$ & 0.00 & $7 \cdot 08$ & 0.00 & $99 \cdot 15$ & 0.01 \\
\hline \multicolumn{7}{|l|}{ D-Fagomine $10 \mathrm{mg} / \mathrm{l}(0.07 \mathrm{~mm})$} \\
\hline S. enterica serovar Typhimurium FVB7654 & 8.56 & 0.01 & 8.53 & 0.00 & $91 \cdot 80$ & 0.06 \\
\hline S. enterica serovar Typhimurium FVB5643 & $8 \cdot 32$ & 0.00 & $8 \cdot 22$ & 0.00 & $78 \cdot 40$ & 0.12 \\
\hline E. coli FVB2453 & 8.09 & 0.00 & $8 \cdot 07$ & 0.00 & $94 \cdot 50$ & 0.01 \\
\hline E. coli FVB3478 & $8 \cdot 27$ & 0.00 & $8 \cdot 24$ & 0.00 & $95 \cdot 10$ & 0.01 \\
\hline L. acidophilus FVB1467 & $6 \cdot 69$ & 0.00 & 6.43 & 0.00 & $54 \cdot 60$ & 0.06 \\
\hline Bifidobacterium sp. FVB4278 & $7 \cdot 08$ & 0.00 & $7 \cdot 08$ & 0.00 & $99 \cdot 17$ & 0.00 \\
\hline \multicolumn{7}{|l|}{ D-Fagomine $20 \mathrm{mg} / \mathrm{l}(0.14 \mathrm{~mm})$} \\
\hline S. enterica serovar Typhimurium FVB7654 & 8.07 & 0.01 & 8.04 & 0.00 & $98 \cdot 20$ & 0.00 \\
\hline S. enterica serovar Typhimurium FVB5643 & 8.47 & 0.00 & 8.45 & 0.00 & 95.50 & 0.00 \\
\hline E. coli FVB2453 & 8.04 & 0.00 & 8.02 & 0.01 & $96 \cdot 30$ & 0.06 \\
\hline E. coli FVB3478 & 8.00 & 0.00 & 8.00 & 0.00 & 99.00 & 0.00 \\
\hline L. acidophilus FVB1467 & 6.71 & 0.01 & $6 \cdot 46$ & 0.00 & $56 \cdot 27$ & 0.01 \\
\hline Bifidobacterium sp. FVB4278 & 8.08 & 0.00 & 8.08 & 0.00 & $99 \cdot 17$ & 0.01 \\
\hline
\end{tabular}

FVB, Facultat Veterinària Barcelona.

* Wells coated with pig mucosa overnight at $4^{\circ} \mathrm{C}$, loaded with the bacterial suspensions in the presence of D-fagomine and incubated at $37^{\circ} \mathrm{C}$ for 90 min Both the attached material and the supernatant were counted for CFU.

We also disclose here an activity of D-fagomine that had never been suggested before: the modulation of bacterial adhesion. We observed that D-fagomine selectively agglutinated potentially deleterious Enterobacteriaceae and prevented their adhesion to pig intestinal mucosa. The adhesion of Lactobacillus spp. was promoted by D-fagomine while that of Bifidobacterium spp. was not affected (Table 2). Fimbriated strains such as E. coli and S. enterica serovar Typhimurium express mannose-specific lectins on the tip of their fimbriae that bind to membrane carbohydrates as a first step in the colonisation of other organisms ${ }^{(35)}$. As D-fagomine is structurally similar to lectin-binding sugars such as mannose (Fig. 1), the observed agglutinating effect is most probably due to the affinity of the iminocyclitol for lectins. Non-fimbriated probiotic strains express other surface adhesins of glycoprotein nature (glycoprotein adhesins) that keep bacteria loosely attached to the intestinal wall ${ }^{(13)}$. These interactions do not appear to be affected by D-fagomine. Notably, D-fagomine did not show any antibiotic effect on any of the strains tested. This is important because other putatively beneficial strains will keep their full viability in the presence of $\mathrm{D}$-fagomine. Thus, the agglutination of Enterobacteriaceae will most probably favour intestinal colonisation by loosely bound non-pathogenic strains such as Bifidobacterium spp. and Lactobacillus spp. and might help to avoid the complications associated with intestinal conditions such as inflammatory bowel disease. As the intestinal microbiota clearly influences the physiological status of the gut and even the health of the whole organism ${ }^{(36)}$, further studies will determine whether this activity of D-fagomine results in longterm effects related to the reduction of health risk factors.
In conclusion, here we report the short-term activity of D-fagomine along the intestinal tract, consisting of effectively lowering the postprandial blood glucose concentration and selectively agglutinating enterobacteria. D-Fagomine effectively modulates the blood glucose response in a dosedependent manner after the ingestion of sucrose or starch, probably by delaying saccharide hydrolysis by brush-border glycosidases. We also show that the results of sucrase inhibition in vitro very much depend on the experimental set-up and cannot account for the activity of inhibitors in vivo. D-Fagomine also inhibits the adhesion of potentially deleterious bacteria to the intestinal mucosa. Based on all this evidence, D-fagomine may be used as a dietary ingredient or functional food component to reduce the health risks associated with an excessive intake of fast-digestible carbohydrates, or an excess of potentially pathogenic bacteria.

\section{Acknowledgements}

The present work was funded by Bioglane SLNE. Support is appreciated from: the Spanish Ministry of Science and Innovation (CDTI-NEOTEC 20080474, AGL2009-12374-C03-03/ALI; CTQ2009-07359); the Catalan regional government (Generalitat de Catalunya, 2009 SGR 00281 and pre-doctoral fellowship to L. G.); and the Panamanian government (SENACYT/IFARHU, pre-doctoral fellowship to E. M.-T.). Possible conflicts of interest: S. P., P. C. and J. L. T. are stockholders of Bioglane SLNE. J. M. P., X. C., M. A. C.-T., S. P., P. C. and J. L. T. designed the research; L. G., E. M.-T., M. E. J. and X. C. conducted the research into blood glucose and sucrase inhibition; M. A. C.-T and C. A. 
conducted the microbiology research; C. L. and S. P. provided essential materials; L. G., E. M.-T., J. M. P. and M. E. J. analysed the data; J. L. T. wrote the paper and had primary responsibility for the final content. All the authors reviewed the paper, and read and approved the final manuscript. Language assistance by Christopher Evans is appreciated.

\section{References}

1. Koyama M \& Sakamura S (1974) Structure of a new piperdine derivative from buckwheat seeds (Fagopyrum esculentum). Agric Biol Chem 38, 1111-1112.

2. Asano N, Yamashita T, Yasuda K, et al. (2001) Polyhydroxylated alkaloids isolated from mulberry trees (Morus alba L.) and silkworms (Bombyx mori L.). J Agric Food Chem 49, 4208-4213.

3. Asano N, Kato A, Miyauchi M, et al. (1997) Specific $\alpha$-galactosidase inhibitors, $\mathrm{N}$-methylcalystegines. Structure/activity relationships of calystegines from Lycium chinense. Eur J Biochem 248, 296-303.

4. Asano N, Tomioka E, Kizu H, et al. (1994) Sugars with nitrogen in the ring isolated from the leaves of Morus bombycis. Carbohydr Res 253, 235-245.

5. Winchester B \& Fleet GWJ (1992) Amino-sugar glycosidase inhibitors: versatile tools for glycobiologists. Glycobiology 2, 199-210.

6. Asano N, Oseki K, Tomioka E, et al. (1994) N-containing sugars from Morus alba and their glycosidase inhibitory activities. Carbohydr Res 259, 243-255.

7. Grundy SM, Brewer HB Jr, Cleeman JI, et al. (2004) Definition of metabolic syndrome: report of the National Heart, Lung, and Blood Institute/American Heart Association Conference on scientific issues related to definition. Circulation 109, 433-438.

8. Lloyd-Jones DM, Hong Y, Labarthe D, et al. (2010) Defining and setting national goals for cardiovascular health promotion and disease reduction: the American Heart Association's strategic impact goal through 2020 and beyond. Circulation 121, 586-613.

9. Lloyd-Jones D, Adams R, Carnethon M, et al. (2009) Heart disease and stroke statistics - 2009 update: a report from the American Heart Association Statistics Committee and Stroke Statistics Subcommittee. Circulation 119, e21-e181.

10. Monsivais P \& Drewnowski A (2007) The rising cost of lowenergy-density foods. J Am Diet Assoc 107, 2071-2076.

11. Drewnowski A \& Specter SE (2004) Poverty and obesity: the role of energy density and energy costs. Am J Clin Nutr $\mathbf{7 9}$, 6-16.

12. Sharon $N$ (2006) Carbohydrates as future anti-adhesion drugs for infectious diseases. Biochim Biophys Acta 1760, 527-537.

13. Lakhtin VM, Lakhtin MV, Pospelova VV, et al. (2006) Lactobacilli and bifidobacteria lectins as possible signal molecules regulating intra- and inter-population bacteria-bacteria and host-bacteria relationships. Part I. Methods of bacterial lectin isolation, physico-chemical characterization and some biological activity investigation. Microb Ecol Health Dis 18, 55-60.

14. Musso G, Gambino R \& Cassader M (2010) Obesity, diabetes, and gut microbiota: the hygiene hypothesis expanded? Diabetes Care 33, 2277-2284.

15. Islam B, Khan SN, Haque I, et al. (2008) Novel antiadherence activity of mulberry leaves: inhibition of Streptococcus mutans biofilm by 1-deoxynojirimycin isolated from Morus alba. J Antimic Chemother 62, 751-757.

16. Majlis S, Björn F, Terry B, et al. (2003) Glycolipid depletion in antimicrobial therapy. Mol Microbiol 47, 453-461.
17. Kato A, Asano N, Kizu H, et al. (1997) Fagomine isomers and glycosides from Xanthocercis zambesiaca. J Nat Prod 60, 312-314.

18. Nojima H, Kimura I, Chen F-J, et al. (1998) Antihyperglycaemic effects of N-containing sugars from Xanthocercis zambesiaca, Morus bombycis, Aglaonema treubii, and Castanospermum australe in streptozotocin-diabetic mice. J Nat Prod 61, 397-400.

19. Castillo JA, Calveras J, Casas J, et al. (2006) Fructose-6phosphate aldolase in organic synthesis: preparation of D-fagomine, N-alkylated derivatives, and preliminary biological assays. Org Lett 8, 6067-6070.

20. Clapés P, Joglar J \& Castillo JA, et al. (2006) Consejo Superior de Investigaciones Científicas; Bioglane, S.L.N.E. Chemoenzymatic process for the preparation of iminocyclitols WO2008025826 (A1), EP2007059062, US2010009417 (A1).

21. Hem A \& Smith AJ (1998) Saphenous vein puncture for blood sampling of the mouse, rat, hamster, gerbil, guinea pig, ferret and mink. Lab Anim 32, 364-368.

22. Dahlqvist A (1964) Method for assay of intestinal disaccharidases. Anal Biochem 7, 18-25.

23. Lee EA, Weiss SL, Lam M, et al. (1998) A method for assaying intestinal brush-border sucrase in an intact intestinal preparation. Proc Natl Acad Sci U S A 95, 2111-2116.

24. Bradford MM (1976) A rapid and sensitive method for the quantitation of microgram quantities of protein utilizing the principle of protein-dye binding. Anal Biochem 72, 248-254.

25. Scofield AM, Fellows LE, Nash RJ, et al. (1986) Inhibition of mammalian digestive disaccharidases by polyhydroxy alkaloids. Life Sci 39, 645-650.

26. FAO/WHO (1998) Carbohydrates in human nutrition. Report of a Joint FAO/WHO Expert Consultation. FAO Food Nutr Pap 66, 1-140.

27. Salmeron J, Ascherio A, Rimm EB, et al. (1997) Dietary fiber, glycaemic load, and risk of NIDDM in men. Diabetes Care 20, 545-550.

28. Ludwig DS (2000) Dietary glycaemic index and obesity. $J$ Nutr 130, 280S-283S.

29. Bischoff H (1994) Pharmacology of alpha-glucosidase inhibition. Eur J Clin Invest 24, 3-10.

30. Solomon TPJ, Haus JM, Kelly KR, et al. (2011) A lowglycaemic index diet combined with exercise reduces insulin resistance, postprandial hyperinsulinemia, and glucose-dependent insulinotropic polypetide responses in obese, prediabetic humans. Am J Clin Nutr 92, 1359-1368.

31. van Baak MA \& Astrup A (2009) Consumption of sugars and body weight. Obes Rev 10, Suppl. 1, 9-23.

32. Nordmann AJ, Nordmann A, Matthias B, et al. (2006) Effects of low-carbohydrate vs low-fat diets on weight loss and cardiovascular risk factors: a meta-analysis of randomized controlled trials. Arch Intern Med 166, 285-293.

33. Dyson PA, Beatty S \& Matthews DR (2007) A lowcarbohydrate diet is more effective in reducing body weight than healthy eating in both diabetic and non-diabetic subjects. Diabet Med 24, 1430-1435.

34. Chaput J-P, Tremblay A, Rimm EB, et al. (2008) A novel interaction between dietary composition and insulin secretion: effects on weight gain in the Quebec Family Study. Am J Clin Nutr 87, 303-309.

35. Tiralongo J \& Moran AP (2009) Bacterian lectin-like interactions in cell recognition and adhesion. In Microbial Glycobiology, pp. 551-565 [AP Moran, O Holst, PJ Brennanand and $\mathrm{M}$ von Itzstein, editors]. San Diego, CA: Academic Press.

36. Sekirov I, Russell SL, Antunes LCM, et al. (2010) Gut microbiota in health and disease. Physiol Rev 90, 859-904. 